\title{
FLNC-Associated Myofibrillar Myopathy
}

\section{New Clinical, Functional, and Proteomic Data}

Rudolf Andre Kley, MD, Yvonne Leber, PhD, Bertold Schrank, MD, Heidi Zhuge, BSc, Zacharias Orfanos, PhD, Julius Kostan, PhD, Adekunle Onipe, PhD, Dominik Sellung, MD, Anne Katrin Güttsches, MD,

Britta Eggers, PhD, Frank Jacobsen, PhD, Wolfram Kress, PhD, Katrin Marcus, PhD,

Kristina Djinovic-Carugo, PhD, Peter F.M. van der Ven, PhD, Dieter O. Fürst, PhD, and Matthias Vorgerd, MD

Neurol Genet 2021;7:e590. doi:10.1212/NXG.0000000000000590

\section{Abstract}

\section{Objective}

To determine whether a new indel mutation in the dimerization domain of filamin C (FLNc) causes a hereditary myopathy with protein aggregation in muscle fibers, we clinically and molecularly studied a German family with autosomal dominant myofibrillar myopathy (MFM).

\section{Methods}

We performed mutational analysis in 3 generations, muscle histopathology, and proteomic studies of IM protein aggregates. Functional consequences of the FLNC mutation were investigated with interaction and transfection studies and biophysics molecular analysis.

\section{Results}

Eight patients revealed clinical features of slowly progressive proximal weakness associated with a heterozygous c.8025_8030delCAAGACinsA (p.K2676Pfs*3) mutation in FLNC. Two patients exhibited a mild cardiomyopathy. MRI of skeletal muscle revealed lipomatous changes typical for MFM with FLNC mutations. Muscle biopsies showed characteristic MFM findings with protein aggregation and lesion formation. The proteomic profile of aggregates was specific for MFM-filaminopathy and indicated activation of the ubiquitin-proteasome system (UPS) and autophagic pathways. Functional studies revealed that mutant FLNc is misfolded, unstable, and incapable of forming homodimers and heterodimers with wild-type FLNc.

\section{Conclusions}

This new MFM-filaminopathy family confirms that expression of mutant FLNC leads to an adult-onset muscle phenotype with intracellular protein accumulation. Mutant FLNc protein is biochemically compromised and leads to dysregulation of protein quality control mechanisms. Proteomic analysis of MFM protein aggregates is a potent method to identify disease-relevant proteins, differentiate MFM subtypes, evaluate the relevance of gene variants, and identify novel MFM candidate genes.

\author{
Correspondence \\ Dr. Kley \\ rudolf.kley@rub.de
}

\section{RELATED ARTICLE}

Editorial

A Window Into the

Myofibrillar Myopathy

Proteome

Page e587

\footnotetext{
From the Department of Neurology (R.A.K., H.Z., D.S., A.K.G., F.J., M.V.), Heimer Institute for Muscle Research, University Hospital Bergmannsheil, Ruhr-University Bochum, Bochum, Germany; Department of Neurology and Clinical Neurophysiology (R.A.K.), St. Marien-Hospital Borken, Borken, Germany; Department of Molecular Cell Biology (Y.L., Z.O., P.F.M.V., D.O.F.), Institute for Cell Biology, University of Bonn, Bonn, Germany; Department of Neurology (B.S.), DKD HELIOS Klinik Wiesbaden, Wiesbaden, Germany; Department of Structural and Computational Biology (J.K., A.O., K.D.-C.), Max Perutz Laboratories, University of Vienna, Vienna, Austria; Medizinisches Proteom-Center (B.E., K.M.), Ruhr-University Bochum, Bochum, Germany; Institute of Human Genetics (W.K.), University of Würzburg, Würzburg, Germany; and Department of Biochemistry (K.D.-C.), Faculty of Chemistry and Chemical Technology, University of Ljubljana, Ljubljana, Slovenia.

Go to Neurology.org/NG for full disclosures. Funding information is provided at the end of the article.

R.A. Kley and Y. Leber contributed equally to this work as co-first authors.

The Article Processing Charge was funded by the authors.
}

This is an open access article distributed under the terms of the Creative Commons Attribution-NonCommercial-NoDerivatives License 4.0 (CC BY-NC-ND), which permits downloading and sharing the work provided it is properly cited. The work cannot be changed in any way or used commercially without permission from the journal. 


\section{Glossary}

CK = Creatine kinase; HGMD = Human Gene Mutation Database; MFMs = Myofibrillar myopathies; NMD = nonsensemediated decay; NADH = Nicotinamide adenine dinucleotide dehydrogenase; SEC-MALS = size exclusion chromatography combined with multiangle light scatt.

Myofibrillar myopathies (MFMs) are hereditary neuromuscular disorders characterized by intramyoplasmic protein aggregation and focal dissolution of myofibrils. ${ }^{1-3}$ A subtype of MFM caused by heterozygous mutations in the FLNC gene (MFM5; MIM\# 609524) was discovered in $2005,{ }^{4}$ and thereafter, additional families with MFM-filaminopathy were described. ${ }^{5-9}$ Main clinical features are progressive skeletal muscle weakness usually manifesting between the fourth and sixth decade of life and respiratory insufficiency in advanced disease stages. MRI reveals a typical pattern of lower limb muscle involvement helpful in differential diagnostics. ${ }^{6,10-12}$ Mutations in FLNC may also lead to a distal myopathy with histopathologic features distinct from $\mathrm{MFM}^{13,14}$ or may cause different types of cardiomyopathies. ${ }^{15}$

The FLNC gene maps to human chromosome 7q32-q35 and is predominantly expressed in striated muscles. FLNc contains an $\mathrm{N}$-terminal actin-binding domain followed by $24 \mathrm{Ig}$-like domains that serve as versatile protein interaction interfaces. The carboxyterminal Ig-like domain 24 forms homodimers, enabling filamins to cross-link actin filaments, ${ }^{16,17}$ which is a crucial function of the filamins. ${ }^{11}$ FLNc binds numerous Z-disc proteins including myopodin/SYNPO $2,{ }^{18}$ FATZ/calsarcin/myozenin, ${ }^{19-21}$ aciculin/
PGM5, ${ }^{22}$ and myotilin, ${ }^{23,24}$ whereas it interacts at the sarcolemma with components of the dystrophin-dystroglycan complex ${ }^{25}$ and acts as scaffold for transmembrane receptors and signaling and adapter proteins.

We characterize the clinical and histopathologic phenotype of a German family with MFM-filaminopathy caused by a novel FLNc mutation in Ig-like domain 24, analyze the molecular pathogenesis, and provide new data about the composition of intramyoplasmic protein aggregates in MFM-filaminopathy.

\section{Patients}

A German family with 9 patients representing 3 generations was included in this study (table e-1, links.lww.com/NXG/A410, figure 1A). Six patients underwent neurologic examinations. From patients I:2 and II:3, only medical information from hospital charts was available. Relatives of patient III:3 reported him to be affected, but he refused clinical examination. Five patients had muscle MRI with a 1.5 T MR unit (MAGNETOM Symphony QUANTUM, Siemens) according to previously published protocols. 5
A

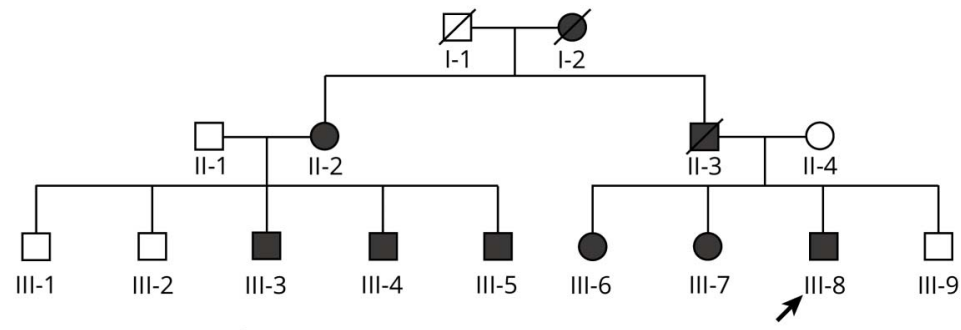

B

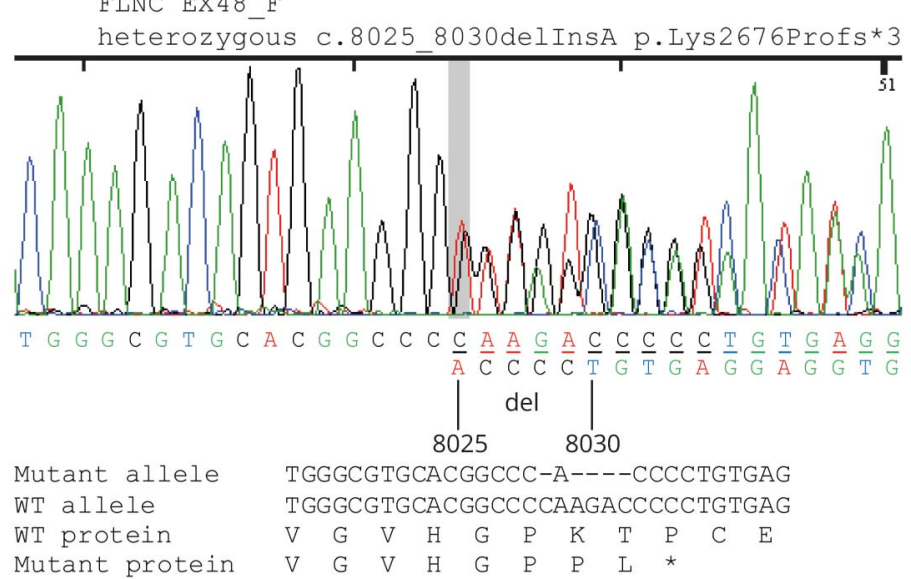

(A) Pedigree of the German family with LGMD-like MFM identified in this study associated with a mutation of FLNC exon 48. The index patient III:8 is indicated by an arrow. Individuals with proven mutation and deceased family members who had muscle weakness are represented by filled symbols. (B) Mutation detection via Sanger sequencing with subsequent translation to amino acids in silico. 


\section{Methods}

\section{Standard Protocol Approvals, Registrations, and Patient Consents}

Informed consent was obtained from all patients (approval of Ruhr-University Bochum ethics committee [\#4078-11]).

\section{FLNC Mutation Detection}

FLNC gene analysis by Sanger sequencing used an established protocol avoiding amplification of the FLNC pseudogene. ${ }^{26}$ Variant detection was accomplished by aligning the obtained sequence with the NCBI Reference Sequence NM_001458.4 using the software Gensearch (Phenosystems, Braine le Chateau, Belgium).

\section{Muscle Biopsy Studies}

Skeletal muscle biopsies from patients III:4 and III:7 were used for evaluating histopathologic changes and for immunolocalization studies, using established procedures. ${ }^{5,6}$

\section{Analysis of Mutant Allele Expression by RT-PCR}

Total RNA was purified from muscle samples using the RNeasy fibrous tissue mini kit (Qiagen, Hilden, Germany). Primer pairs used were as follows: (1) ctccagctacagctccatcc and gaggcacttttgggattcaa or (2) catcgtgaacaccctgaatg and gacactttcgtcaccccact. Amplicons were purified, digested with AleI, run on agarose gels, and were analyzed with a gel documentation system (BioRad GelDoc XR) and band densitometry (QuantityOne software).

\section{Cloning of Truncated and Full-Length FLNC Constructs}

A FLNC d23-24 construct containing the c.8025_8030delCAAGACinsA mutation was obtained by PCR using primers tttacgcgtGGGGAGCAGAGCCAGGCTGGGGACCCAG (forward) and tttgtcgacCAGGGGTGGGCCGTGCACGCCCACCATCATC (reverse, without stop codon) or tttgtcgacTCACAGGGGTGGGCCGTGCACGCCCACCATC (reverse, including stop codon) and the wild-type variant as a template. Amplicons were cloned into the prokaryotic expression vectors pET23-EEF, pET23-T7, or pGEX-6P3 for expression of fusion proteins carrying a C-terminal His-tag and either a C-terminal EEF- or N-terminal T7-immunotag or an N-terminal GST-tag, respectively. Integrity of all constructs was verified by sequencing (LGC Genomics, Berlin, Germany).

Full-length FLNC cDNA clones in pEGFP-C2 (Clontech, Takara Holdings, Kyoto, Japan) were obtained as described. ${ }^{13}$ The mutation was introduced into full-length FLNC by exchanging the cDNA encoding the wild-type Ig-like domains 23-24 with the truncated variant using a unique BspEI restriction site within the cDNA encoding Ig-like domain 23.

Details of expression and purification of recombinant proteins, biophysical characterization, cross-linking of FLNc polypeptides, and proteolytic susceptibility studies are provided in table e-2, links.lww.com/NXG/A411.

\section{Transfection Studies}

C2C12 cells were cultured in 6-well plates (TPP, Trasadingen, Switzerland) in Dulbecco's modified Eagle medium supplemented with $15 \%$ fetal calf serum, $4 \mathrm{mM}$ L-glutamine, $1 \%$ nonessential amino acids, and $2 \mathrm{mM}$ sodium pyruvate (Invitrogen) and transfected with full-length wild-type or mutant FLNC constructs (see above) using Lipofectamine LTX and Plus Reagent according to the manufacturer's instructions (Invitrogen). Twenty-four hours after transfection, aggregate formation was evaluated in at least 2,000 transfected cells for each construct by live cell imaging (IX83 microscope, Olympus, Tokyo, Japan). Unpaired $t$ tests were used for statistical analysis.

\section{Proteomic Analysis}

Differential proteomic analysis was performed with samples of 2 patients carrying the p.K2676Pfs* 3 mutation (III:4 and III: 7) and 5 patients with distinct FLNC mutations (3 with p.W2710X and 2 with p.V930_T933del mutation). The latter patients were also included in our previous proteomic study ${ }^{27}$ but were reanalyzed with an optimized method.

Combined laser microdissection label-free mass spectrometry was applied as described. ${ }^{15,28} 250,000 \mu \mathrm{m}^{2}$ of protein aggregates and control samples were excised from immunostained $10 \mu \mathrm{m}$ cryosections by laser microdissection (LMD 6500; Leica Microsystems, Wetzlar, Germany) and transferred to reaction tubes containing $40 \mu \mathrm{L}$ formic acid (FA, 98\%-100\%). Samples were incubated at room temperature for 30 minutes in the sonication bath $(35 \mathrm{kHz})$ and centrifuged for $10 \mathrm{~min}$ utes $\left(12,000 \mathrm{~g}, 4^{\circ} \mathrm{C}\right)$, and supernatant proteins were further processed by tryptic digestion ${ }^{15}$ or stored at $-80^{\circ} \mathrm{C}$ until use.

Samples were analyzed by nanoHPLC-ESI-MS/MS on an UltiMate 3000 RSLC nanoLC system coupled to a LTQ Orbitrap Elite mass spectrometer (Thermo Fisher Scientific, Bremen, Germany). Protein quantification was performed by spectral counting. Nano LC-MS/MS and subsequent data analysis parameters were as described. ${ }^{28}$ Overrepresentation of proteins in aggregate samples was calculated, and a 2-tailed unpaired $t$ test (equal variances assumed) was used for each protein. A protein was considered as significantly increased with a fold change $>1.5$ and $p$ value $\leq 0.05$.

\section{Data Availability}

Anonymized data not published within this article will be shared by request from any qualified investigator.

\section{Results}

\section{Identification of a Novel FLNC Mutation}

We describe a 3-generation family with MFM-filaminopathy with 9 affected patients (figure 1A). Sanger sequencing of the FLNC gene of the index patient revealed a novel indel mutation c.8025_8030delCAAGACinsA segregating in this family with the disease (figure 1B). This combination of deletion and 
A

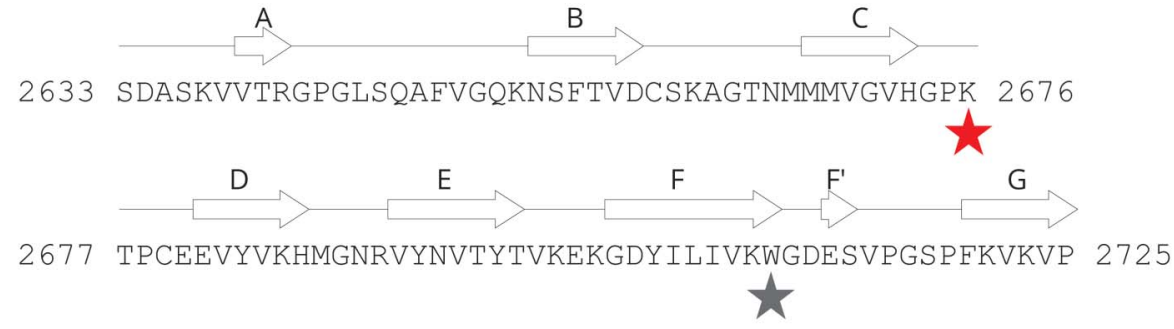

B

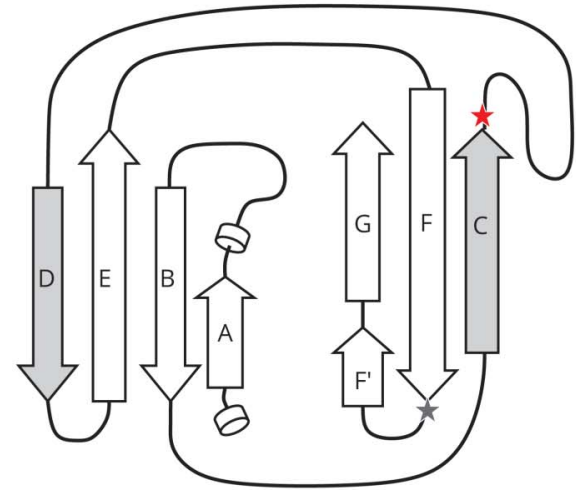

C

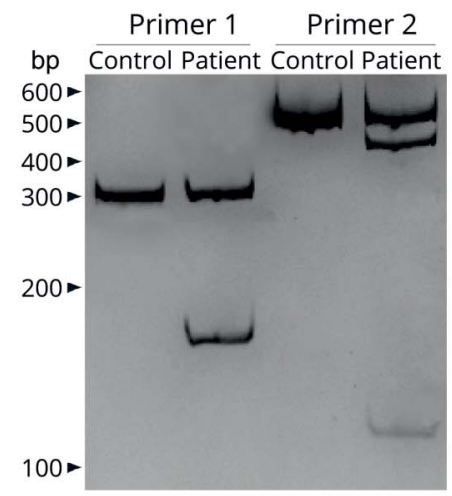

(A and B) Sketch illustrating the effect of the mutation. Topology of filamin $C$ domain 24 as derived from its crystal structure $^{17}$ aligned to the amino acid sequence $(A)$ and in a 2-dimensional view (B). $\beta$-strands ( $C$ and $D$ ) form the interface between dimerized domains. Strand $G$ directly interacts with strand $(A)$, which is important for the coherence of the 2 $\beta$-sheets that comprise an Ig-like domain. The position of the p.K2676Pfs*3 mutation is marked with a red asterisk. It results in the loss of $\beta$-strands (D-G) rendering a correct folding of the domain impossible. The gray asterisk marks the position of the p.W2710X mutation. (C) RT-PCR of control and patient cDNA digested with Alel. cDNA reverse transcribed from control and patient skeletal muscle mRNA amplified with 2 different primer pairs and digested with Alel. Because control cDNA does not contain an Alel restriction site, only mutant cDNA was digested into 160 and $170 \mathrm{bp}$ fragments (primer pair 1) and 450 and 138 bp fragments (primer pair 2), respectively. In patient skeletal muscle, wild-type and mutant mRNA are expressed in an approximate ratio of 4:3. simultaneous insertion results in a frameshift, producing a premature stop codon at position 2679 (p.K2676Pfs*3).

Similar to the previously reported c.G8130A (p.W2710X) mutation found in several unrelated filaminopathy families, the mutation found in the German family reported here truncates the dimer-forming FLNc Ig-like domain 24. Although in the p.W2710X mutation, the carboxyterminal 16 amino acids are deleted, the c.8025_8030delCAAGACinsA, p.K2676Pfs*3 mutation leads to replacement of the carboxyterminal 50 amino acids by proline and leucine (figure $1 \mathrm{~B}$ ). The mutation therefore results in the deletion of $\beta$-strands $D, E, F, F^{\prime}$, and $G$ from the Ig-like domain 24 (d24) (figure 2, A and B).

For premature stop codon-causing mutations, it is crucial to check for mutant mRNA degradation via nonsense-mediated decay (NMD). We therefore performed RT-PCR with cDNA from mRNA purified from control and patient skeletal muscles. At the cDNA level, the mutation leads to the generation of an AleI restriction site, enabling us to use different primer pairs to amplify patient and control cDNAs, and a subsequent AleI digestion. Patient cDNA exhibited both wild-type and mutant cDNAs at a ratio of approximately $4: 3$ (figure $2 \mathrm{C}$ ), indicating that mutant mRNA is not degraded via NMD and that both wild-type and mutant RNAs are expressed in patients.

\section{Clinical Features}

In the 8 affected patients whose data were available, disease onset was diagnosed between 35 to 45 years (mean age $37.4 \pm$ 3.0 years, table e-1, links.lww.com/NXG/A410). In all patients, the initial symptom was proximal leg muscle weakness. The disease course was slowly progressive with additional distal leg and upper limb weakness. At an advanced stage, 3 patients used a wheelchair. Cardiomyopathy occurred in $2 / 8$ patients and respiratory insufficiency in $4 / 8$ patients. Creatine kinase (CK) elevation was moderate and $<7$-fold of the upper normal limit. Muscle MRI of patient III:4 showed severe symmetrical lipomatous alterations in most posterior thigh muscles (semimembranosus, adductor magnus and longus, semitendinosus, and biceps femoris), in vastus intermedius and in the soleus (figure 3). In lower legs, a reticular pattern of hyperintensity on T1-weighted images was observed in the medial head of gastrocnemius and in tibialis anterior, extensor hallucis longus, and extensor digitorum longus muscles. The pattern of muscle involvement was similar in patient III:5 but ventral thigh muscles, tibialis anterior and the medial head of gastrocnemius were more severely affected than in patient III:4. MRI detected no alterations in the gracilis and in the lateral head of gastrocnemius. In patients with a shorter disease duration, reticular changes occurred either in the anterior tibialis and semimembranosus (III:6) or in the soleus (III:7, III:8) muscle (figure 3) as early degenerative changes.

\section{Histopathologic Studies}

Muscle biopsies of patients III:4 and III:7 showed dystrophiclike features with fiber size variation with scattered atrophic and hypertrophic fibers, fiber splitting, increased numbers of centrally located nuclei, augmented fibrosis, and fatty infiltrations. These features were more pronounced in patient III: 4 (figure 4A) compared with those in III:7 (figure 4B). Additional structural changes with rimmed vacuoles appeared in some muscle fibers. Trichrome staining (TC) showed muscle 


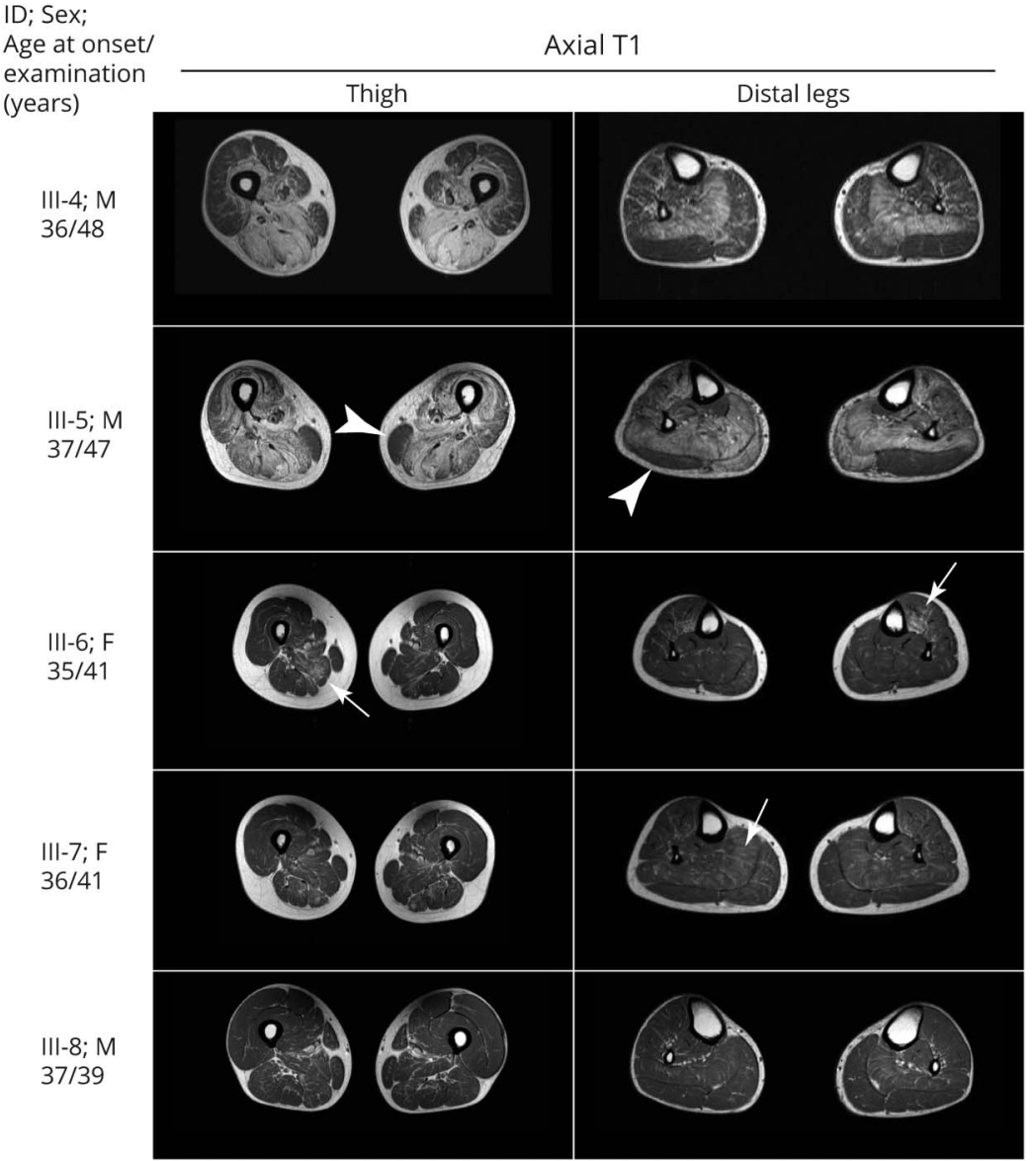

T1-weighted muscle MRI revealed severe fatty degenerative changes in patients III:4 and III:5 with a disease duration of more than 10 years. The gracilis and the lateral head of the gastrocnemius were relatively spared in both patients, as indicated by arrowheads. Mild early changes (arrows) were seen either in the tibialis anterior and semimembranosus (patient III:6) or in the soleus muscle (patients III:7 and III:8). fibers with a combination of vacuolar changes and bluecolored amorphous deposits (figure 4, A.b and B.b). Nicotinamide adenine dinucleotide dehydrogenase (NADH) staining demonstrated areas devoid of oxidative enzyme activities in many fibers and areas of increased $\mathrm{NADH}$ intensities outside these lesions and beneath the sarcolemma (figure 4, A.c and B.c). Immunolocalization studies revealed accumulation of FLNc and desmin in protein aggregates within abnormal muscle fibers (figure 4, C and D.c).

Because muscle fibers of patients with MFM caused by other FLNc mutations and of p.W2711X knock-in mice contain large numbers of myofibrillar lesions, we also stained longitudinal sections of our patients for lesion markers desmin, FLNc (figure 4, E.a-c), myotilin, and Xin (not shown). This revealed that also in patients with p.K2676Pfs*3 mutation, these proteins were not only localized in the typical aggregates but also in frequently occurring microlesions and macrolesions (myofibrillar lesions spanning up to 5 sarcomeres or more than 5 sarcomeres and across multiple myofibrils, respectively).

\section{Proteomic Analysis of Protein Aggregates}

Mass spectrometric analysis detected 1045 proteins, with 88 being significantly overrepresented in aggregate samples compared with intraindividual control samples from muscle fibers without aggregates (table e-3, links.lww.com/NXG/ A412). From these 88 proteins, the disease-causing FLNc showed the highest mean proportion in aggregates with a value nearly 7 -fold higher than in control samples. In relation to proportion, Z-disc and Z-disc-associated proteins represented the most important group of accumulated aggregate proteins, followed by quality control and protein degradation proteins (figure 5). Subgroup analysis of different FLNC mutations revealed high similarity of proteomic aggregate profiles in all patients with MFM-filaminopathy (figure 5). Comparison of this MFM-filaminopathy cohort with proteomic findings in 96 other MFM patients, including patients with mutations in other known MFM genes and genetically unresolved cases, revealed that an FLNc ratio (value in aggregate sample divided by the value in intraindividual control sample) above 5 is a highly sensitive (100\%) and specific (99\%) diagnostic marker for MFM-filaminopathy (data not shown).

\section{Biophysical and Biochemical Studies of Mutant p.K2676Pfs*3 FLNc Protein}

We examined effects of the p.K2676Pfs ${ }^{*} 3$ mutation on fold integrity and stability. Circular dichroism spectroscopy was used to assess secondary structure content of the mutant 


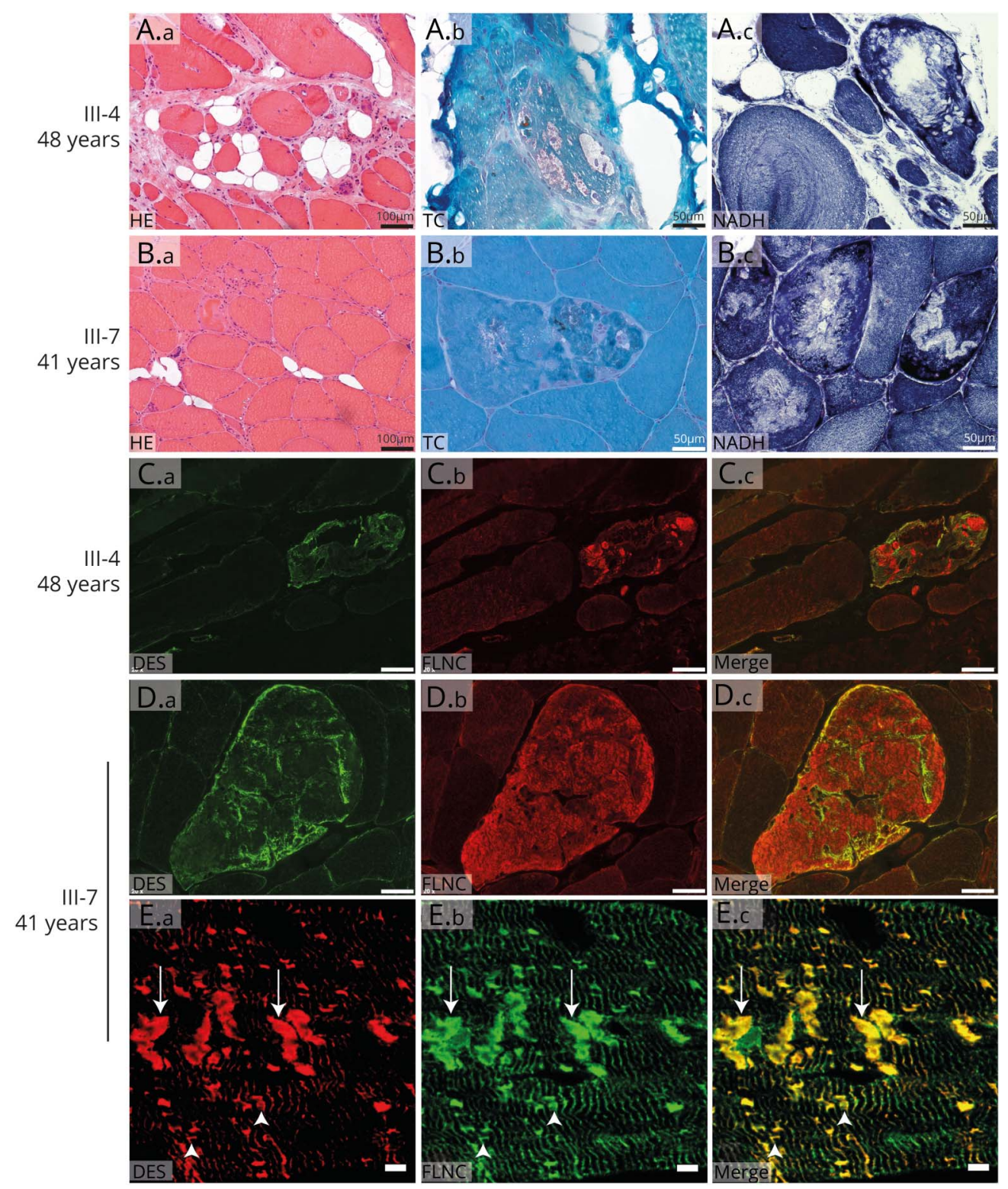

Analysis of muscle biopsy samples from patients III:4 (A and C) and III:7 (B, D, and E). (A.a and B.c) Cryosections stained with H\&E, TC, and NADH showed fiber diameter variability, fiber splitting, adipose replacement, endomysial fibrosis, increase in central nuclei, and marked irregularities of the intermyofibrillar network with many fibers showing multiple areas devoid of oxidative enzyme activity. These findings were more pronounced in III:4. (C.a-D.C) Cryosections double stained with antibodies recognizing desmin (DES) and FLNc to localize protein aggregations. Bar: $50 \mu \mathrm{m}$. (E.a-E.c) Longitudinal cryosections were double stained for DES and FLNc. Both proteins colocalized in aggregates (arrows), but also in microlesions (arrowheads). Bar: $10 \mu \mathrm{m}$.

constructs comprising Ig-like domains 23-24 (d23-24). Whereas analysis of the wild-type domains resulted in the typical $B$-strand secondary structure previously reported for these domains, ${ }^{16,17}$ the truncated mutant construct resulted in lower signals (figure 6B) for $B$-strand structure with a concomitant increase of signal for random coil, suggesting improper folding. Structure stability was analyzed by thermolysin digestion of $\mathrm{d} 23-24$ constructs. The mutant p.K2676Pfs*3 protein was already partially digested after 1 minute and completely digested after 20 minutes, whereas a portion of the p.W2710X mutant and almost all of the wildtype variant was still intact after this time (figure $6 \mathrm{C}$ ), indicating a notably less stable fold of especially the p.K2676Pfs 3 mutant protein with exposed unfolded regions highly susceptible to proteolysis. We next inspected dimerization of mutant FLNc by chemical cross-linking experiments. Whereas the cross-linking of the wild-type variant yielded a strong signal for dimer and the spontaneous aggregation of the p.W2710X mutant was reproduced, crosslinking of the p.K2676Pfs ${ }^{*} 3$ mutant d23-24 did not yield dimeric cross-links, indicating impaired dimer formation (figure 6D). To assess the hydrodynamic properties and measure the molecular mass of the p.K2676Pfs*3 d23-24 protein in solution, we used size exclusion chromatography 


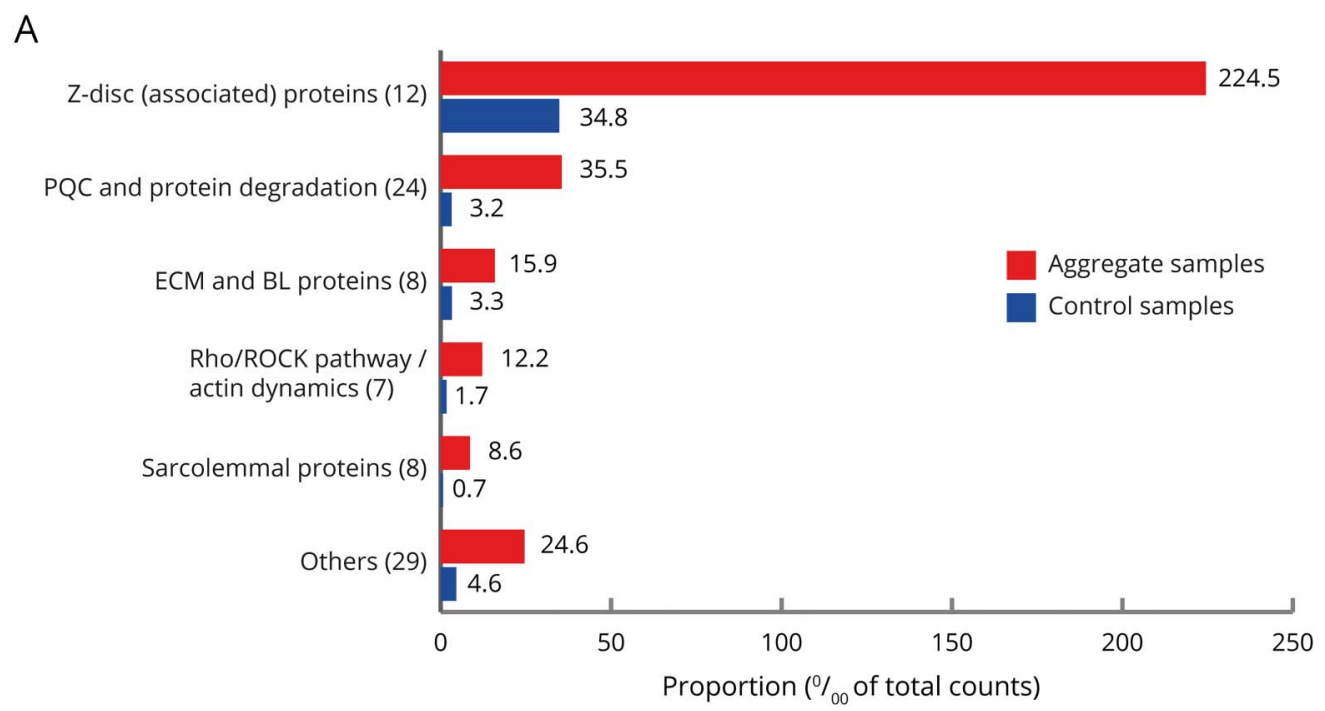

B
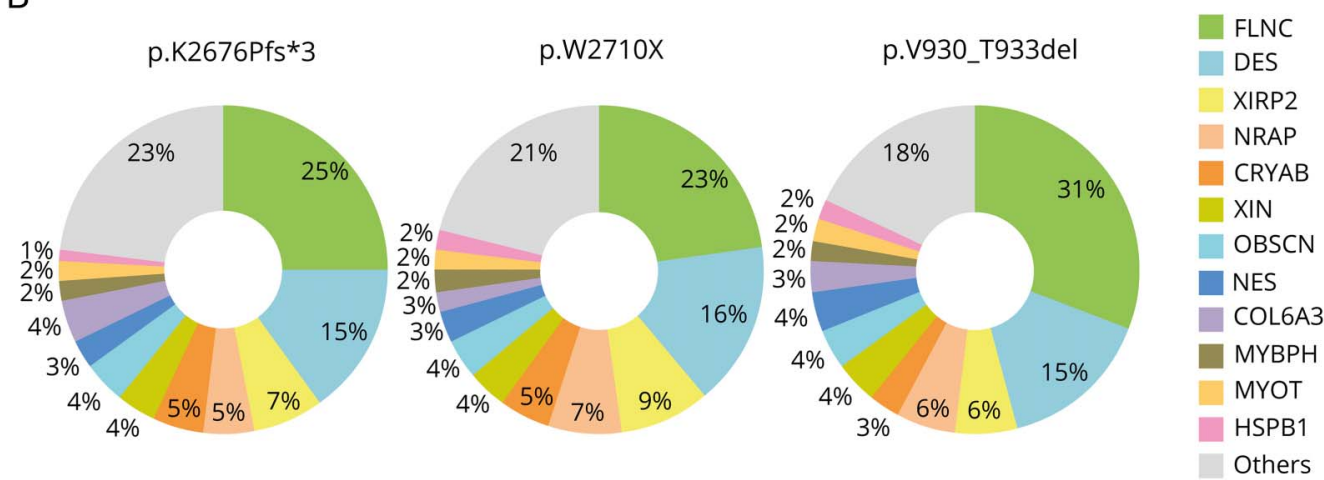

Aggregate and intraindividual control samples were collected by laser microdissection. The bar chart in (A) shows the proportion of proteins identified as overrepresented in aggregate samples (compared with controls), grouped by function. Z-disc and Z-disc-associated proteins were the most abundant components followed by proteins involved in protein quality control and degradation. (B) Proteomic profiles of overrepresented aggregate proteins in patients with filaminopathy caused by different FLNC mutations. Pie charts illustrate that the pattern in patients with p.K2676Pfs*3 mutation was highly similar to that in patient with p.W2710X or p.V930_T933del mutation. FLNc was always the most abundant protein, followed by desmin and the FLNc binding partners Xin actin-binding repeat-containing protein 2 (XIRP2) and nebulin-related-anchoring protein (N-RAP). Proportions of aB crystallin, Xin actin-binding repeat-containing protein 1 (Xin), obscurin, and nestin were also similar.

combined with multiangle light scattering (SEC-MALS). Whereas the wild-type construct $\mathrm{d} 23-24$ eluted at a volume expected for a dimer and displayed a molecular mass of 48.9 $\mathrm{kDa}$ as assessed by MALS, the p.K2676Pfs*3 mutant d23-24 clearly displayed a monomeric state with a nonsymmetric elution profile suggesting a folding defect and structural disorder (figure e-1A, links.lww.com/NXG/ A409). Taken together, our data reveal that the deletion mutant is impaired in dimerization due to an incomplete, unfolded domain 24.

\section{Transfection Studies}

To analyze effects of expression of mutant FLNc in C2C12 myoblasts, we transiently transfected these cells with constructs encoding full-length wild-type or mutant FLNc. Imaging of more than 5,000 successfully transfected cells revealed that spontaneous aggregate formation was significantly more frequent in cells expressing mutant FLNc compared with wild-type controls $(2.4 \%$ vs $1.2 \%, p<0.0001$, figure e-1B, links.lww.com/NXG/A409).

\section{Discussion}

Mutations in FLNC may lead to MFM, distal myopathy, or a variety of familial and isolated cardiac phenotypes. ${ }^{7}$ MFMfilaminopathy is associated with mutations in the rod domain of FLNc causing truncation of the dimerization domain or other protein alterations leading to misfolding and aggregation. ${ }^{4,8,29}$ The few reported examples of distal myopathies either result from mutations in the ABD of FLNc, ${ }^{13}$ or are caused by haploinsufficiency due to NMD of the mutant transcript. ${ }^{14}$ We here describe an MFM-filaminopathy family with a novel indel mutation in one of the exons encoding the dimerization domain of FLNc and characterize its pathogenic consequences. 
A

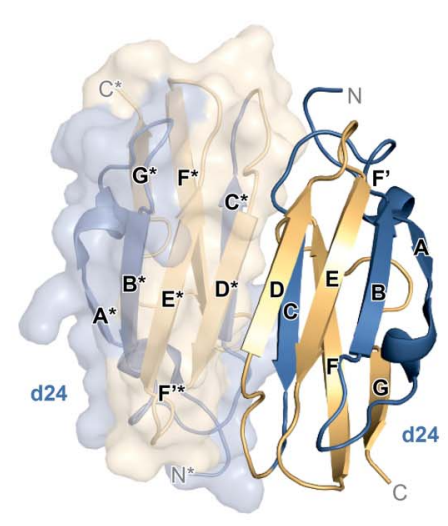

C

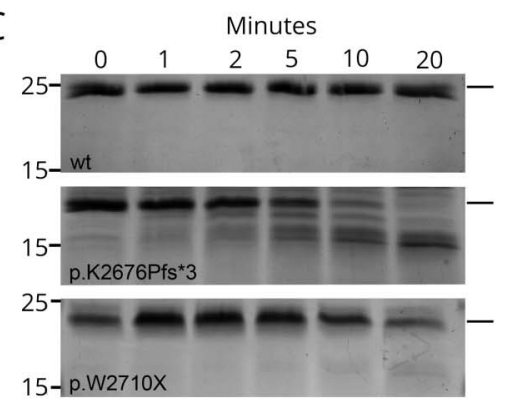

B

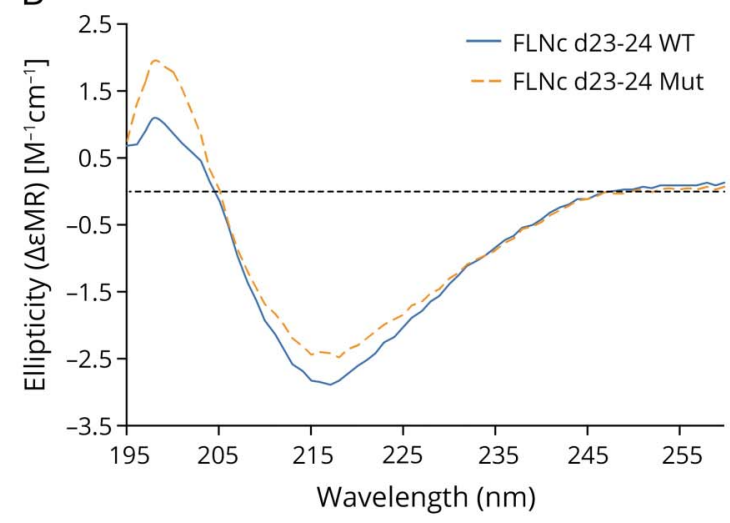

D

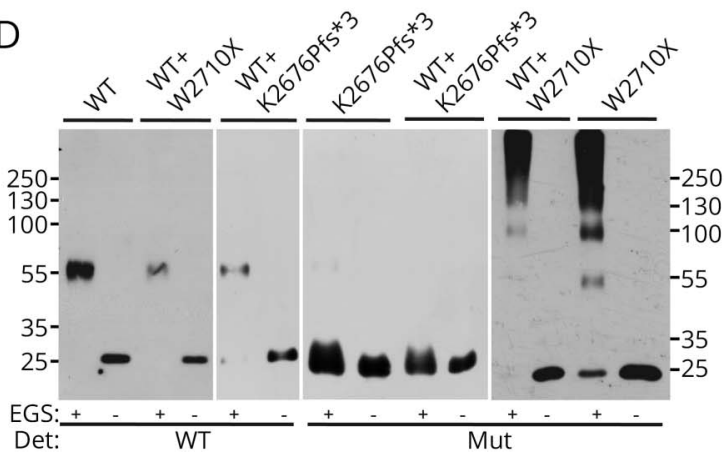

(A) Ribbon representation of the human FLNc domain 24 structure (PDB code 1V05). The d24 dimer is shown in blue with regions missing in the p.K2676Pfs*3 mutant variant shown in light orange. $\beta$-strands as well as $\mathrm{N}$ and $\mathrm{C}$ termini are indicated. Asterisks distinguish $\beta$-strands of individual subunits. The mutation leads to loss of $\beta$-strands involved in the formation of 2 extended antiparallel $\beta$-sheets (B-E-D-D*-E*-B* and C-F-G-G* F*-C*), which stabilize domain fold integrity as well as the dimer, leading to severely impaired dimerization. (B) Circular dichroism spectroscopy performed with purified, bacterially expressed wild-type and p.K2676Pfs*3 mutant FLNc d23-24 constructs. The mean residue ellipticity ( $\Delta \varepsilon$ MR) of wild-type and mutant FLNc shows a minimum at 218 nm characteristic of a $\beta$-structure. However, the deletion mutant displays a lower amplitude at this wavelength, indicating loss of $\beta$-structure and/or folding. (C) Thermolysin digestion of wild-type and mutant FLNc d23-24 for 1-20 minutes. The mutant protein was completely digested after 20 min, whereas almost all the wild-type variant was still intact, and the p.W2710X was only partially digested, indicating less stable folding of the p.K2676Pfs*3 mutant protein. (D) Chemical cross-linking experiments using wild-type (WT) and mutant filamin d23-24 constructs. Without EGS, only monomers of all constructs were detected (approximately 20-25 kDa). After cross-linking with EGS, the wild-type variant appears as dimers ( $\sim 50 \mathrm{kDa})$, the mutant p.W2710X construct was mainly found in high-molecular-mass aggregates, and p.K2676Pfs*3 was only found as monomers. In a mixture of differentially tagged wild-type and both mutant constructs (WT + p.W2710X and WT + p.K2676Pfs*3), the wild-type construct dimerizes normally. Note that samples were in part run on different gels that are separated by a white line.

In this family, clinical disease manifestation with proximal lower limb weakness started in the fourth or fifth decade of life. In later disease stages, distal lower limb, upper limb, and respiratory muscles were also involved. A fraction of patients showed cardiac abnormalities, and the CK level was moderately elevated, coinciding with descriptions of MFM-filaminopathy families from different countries and with distinct FLNC mutations. ${ }^{29}$ This underlines that this type of FLNC-associated myopathy, which is associated with the expression of a toxic protein and formation of protein aggregates in muscle fibers, is characterized by a largely homogeneous clinical phenotype differing from the phenotypes caused by mutations in the ABD of FLNC, ${ }^{30}$ mutations resulting in reduced expression of FLNc protein, ${ }^{14}$ or MFM subtypes due to mutations in other genes. ${ }^{31}$

Muscle imaging findings at more advanced disease (III:4 and III: 5) were also typical of MFM-filaminopathy with a pattern of muscle involvement that met the criteria defined to differentiate between this disease and other MFM subtypes. ${ }^{10,12}$ As in other families with MFM-filaminopathy, the gracilis, sartorius, and the lateral head of the gastrocnemius muscle were relatively spared, although neighboring muscles already showed marked lipomatous changes. Imaging in younger patients with shorter disease duration (III:6, III:7, and III:8) revealed only slight muscle alterations that were not sufficient for a clear distinction against other myopathies, demonstrating the sometimes limited differential diagnostic value of muscle imaging in early disease stages.

The most impressive histopathologic feature in our patients was massive protein aggregation with increased immunoreactivity for FLNc and other MFM marker proteins in their muscle fibers. To further decipher the composition of protein aggregates in MFM-filaminopathy, we extended our previous proteomic studies by analyzing material from these patients and optimizing our approach. From the 88 proteins significantly overrepresented in aggregates, FLNc contributed the highest 
quantity of peptides in aggregate samples, followed by further Z-disc and Z-disc-associated proteins. Our previous proteomic studies only identified 28 of these proteins. ${ }^{27}$ Several of these newly identified, less abundantly overrepresented proteins are involved in protein degradation and protein quality control, e.g., SQSTM1 (p62), HSPA8 and BAG3. The latter are components of chaperone-assisted selective autophagy (CASA), a tension-induced autophagy pathway essential for myofibril integrity maintenance by degradation of damaged FLNc, and simultaneous stimulation of FLNC transcription. ${ }^{32}$ These findings are consistent with our previous hypothesis-driven immunolocalization studies in MFM-filaminopathy ${ }^{29}$ and with results of proteomic analyses in MFM-myotilinopathy. ${ }^{28}$ We succeeded in identifying further chaperones and proteins involved in different cellular pathways as aggregate components. This increases our understanding of the disease pathogenesis and might help to develop new therapeutic strategies, e.g., by influencing CASA activity. Additional interesting proteins overrepresented in aggregate samples are the FLNc binding partners phosphoglucomutase-like protein 5 (PGM5, aciculin) and HSPB7, both being essential for assembly, remodeling and maintenance of myofibrils. ${ }^{22,33}$ Furthermore, HSPB7 protein expression levels were highly reduced in muscle fibers of homozygous p.W2711X knock-in mice. Together with the finding that proteins associated with other MFM subtypes (desmin, myotilin, alphaB-crystallin and BAG3) also accumulate in MFM-filaminopathy aggregates, these data render PGM5 and HSPB7 promising candidate genes for new MFM subtypes. Therefore, we recommend testing genetically unresolved patients with MFM for mutations in both genes. It is also noteworthy that similar strategies to identify disease genes by combination of laser microdissection and proteomic analysis were already successful in other protein aggregate myopathies (Refs. 34 and 35 and our unpublished data).

Another clinically relevant point is that proteomic analysis can be helpful in differential diagnostic workup of patients with MFM. Our analyses revealed that proteomic aggregate profiles in 7 patients with MFM-filaminopathy with 3 distinct FLNC mutations were highly similar. Moreover, we could validate in a large MFM cohort that the FLNc ratio, i.e., the proportion of FLNc in aggregate samples divided by the proportion of FLNc in intraindividual control samples, is a highly sensitive and specific diagnostic biomarker. All patients with MFM-filaminopathy but only 1 of 96 patients with different MFM subtypes had an FLNc ratio above 5. Together with clinical and muscle imaging findings, this biomarker is useful to assess FLNC variants of uncertain significance in patients with MFM.

The indel mutation we describe here causes a frameshift introducing a stop codon in the mutant mRNA. In the Human Gene Mutation Database (HGMD; hgmd.cf.ac.uk/ ac/index.php), only $1.4 \%$ of the total number of human mutations identified are indel mutations, making this type of mutation very rare. ${ }^{36}$ Indeed, in a recent article reporting 325 different variants of the FLNC gene, only 4 of those (1.2\%) were indel mutations. ${ }^{7}$ The region directly flanking the p.K2676Pfs*3 mutation detected in our family (GGTGGGCGTGCACGGCCCCAAGACCCCCTGTGA GGAGGTG, deleted nucleotides are underlined) is very GC-rich (72.5\%), and stretches of 4 or 5 guanines or cytosines, often flanked by an adenine or thymine, were identified as hotspots for human mutations. ${ }^{37}$ It is interesting to note that also 2 different MFM-causing mutations in Ig-like domain 24 of FLNc are localized in a stretch of 4 guanines flanked on both sides by a thymine (NM_001458.4(FLNC):c.8130G $>$ A and c.8129G $>A^{4,9}$ ). Both mutations result in the same mutation at the protein level (p.W2710X), indicating that this specific stretch of guanines indeed is a mutation hotspot. Because the introduced stop codon occurs in the last exon, NMD does not occur, as confirmed by our RT-PCR experiments, indicating that a misfolded and unstable FLNc variant is indeed expressed, which not only leads to protein aggregation but also results in the formation of numerous myofibrillar lesions. Notably, p.K2676Pfs*3 FLNc was even more susceptible to proteolysis than p.W2710X FLNc. Because muscle fibers of p.W2711X knock-in mice with the latter human FLNc mutation contain myofibrillar lesions, but no aggregates, we proposed that lesions are precursors of aggregates and contribute to muscle weakness. ${ }^{38}$ Thus, myofibrillar lesions and protein aggregates are hallmarks of MFM-filaminopathy.

Loss of $\beta$-strands $\mathrm{F}^{\prime}$ and $\mathrm{G}$ (figure $2, \mathrm{~A}$ and $\mathrm{B}$ ) caused by the p.W2710X mutation is sufficient for the inability of Ig-like domain 24 to dimerize. ${ }^{4,39}$ Instead, multimeric complexes are formed, indicating spontaneous aggregation. Deletion of $\beta$-strands D-G in the patients described here also has severe effects: the ability to dimerize is entirely lost, and spontaneous aggregation is displayed in vitro. Indeed, fulllength mutant FLNc formed significantly more aggregates in transfected myoblasts than wild-type protein, in line with observed increased levels of proteins involved in degradation and protein quality control in aggregates. Together with our previous data on a mutation in Ig-like domain $7^{29,38}$ and the presence of other MFM-filaminopathy causing mutations in other Ig-like domains, ${ }^{15}$ this might indicate that the mere misfolding of any single Ig-like domain of FLNc is sufficient to cause a phenotype with lesion and aggregate formation.

\section{Conclusion}

In conclusion, we have identified a rare indel mutation in a potential mutation hotspot in FLNC that is associated with MFM-filaminopathy in a German family of 3 subsequent generations. Here, we characterized the disease phenotype and the mutated protein at different levels and found that this mutation causes a pattern typical for various types of protein aggregate-forming MFM-filaminopathies. In addition, we demonstrate a highly similar composition of protein 
aggregates in all MFM-filaminopathy subtypes, independent of the individual FLNC mutation causative for this disease. Therefore, we suggest this tool as a sensitive and specific diagnostic biomarker in patients with MFM and FLNC variants of unknown significance. We also identified promising candidate genes for new MFM subtypes.

\section{Acknowledgment}

The authors thank the patients for participation in this study and Aileen Balkow, Karin Bois, and Anja Schreiner for technical support.

\section{Study Funding}

This research was supported by the German Research Foundation (DFG Research Unit 1228 and DFG Research Unit 2743), the Heimer foundation, ITN-MUZIC (N²38423), FWF Projects I525, I1593, P22276, P19060, and W1221, "Laura Bassi Centre of Optimized Structural Studies” (N²53275), Welcome Trust Collaborative Award (201543/Z/16/Z), COST action BM1405, WWTF Chemical Biology project LS17-008, Christian Doppler Laboratory for High-Content Structural Biology and Biotechnology, the Welcome Trust Collaborative Award, the Centre of Optimized Structural Studies, the AustrianSlovak Interreg Project StruBioMol (B301), and by the Doctoral Program Plus Structure and Interaction of Biological Macromolecules (W1221).

\section{Disclosure}

R.A. Kley was funded by DFG Research Unit 1228 and received research support from the Heimer foundation. Y. Leber, B. Schrank, H. Zhuge, and Z. Orfanos report no disclosures. J. Kostan was funded by the Welcome Trust Collaborative Award, by Centre of Optimized Structural Studies, and by Austrian-Slovak Interreg Project StruBioMol (B301). A. Onipe was funded by Doctoral Program Plus Structure and Interaction of Biological Macromolecules (W1221). D. Sellung, A.-K. Güttsches, B. Eggers, F. Jacobsen, and W. Kress report no disclosures. K. Marcus was funded by DFG Research Unit 1228. K. DjinovicCarugo was funded by ITN-MUZIC (N²38423), FWF Projects I525, I1593, P22276, P19060, and W1221, "Laura Bassi Centre of Optimized Structural Studies” ( $\mathrm{N}^{\circ} 253275$ ), Welcome Trust Collaborative Award (201543/Z/16/Z), COST action BM1405, WWTF Chemical Biology project LS17-008, and Christian Doppler Laboratory for HighContent Structural Biology and Biotechnology. P.F.M. van der Ven reports no disclosures. D.O. Fürst was funded by DFG Research Units 1228 and 2743. M. Vorgerd received research support from the Heimer Foundation. Go to Neurology.org/NG for full disclosures.

\section{Publication History}

Received by Neurology: Genetics July 23, 2020. Accepted in final form December 28, 2020.

\section{Appendix Authors}

\begin{tabular}{|c|c|c|}
\hline Name & Location & Contribution \\
\hline $\begin{array}{l}\text { Rudolf } \\
\text { Andre } \\
\text { Kley, MD }\end{array}$ & $\begin{array}{l}\text { Ruhr-University Bochum, } \\
\text { Bochum, Germany and St. } \\
\text { Marien-Hospital, Borken, } \\
\text { Germany }\end{array}$ & $\begin{array}{l}\text { Designed and conceptualized } \\
\text { the study; major role in the } \\
\text { acquisition and interpretation of } \\
\text { data; and drafted the manuscript } \\
\text { for intellectual content. }\end{array}$ \\
\hline $\begin{array}{l}\text { Yvonne } \\
\text { Leber, PhD }\end{array}$ & $\begin{array}{l}\text { University of Bonn, Bonn, } \\
\text { Germany }\end{array}$ & $\begin{array}{l}\text { Acquisition and } \\
\text { interpretation of data and } \\
\text { drafted the manuscript for } \\
\text { intellectual content. }\end{array}$ \\
\hline
\end{tabular}

\begin{tabular}{lll}
\hline Bertold & DKD HELIOS Medical & Acquisition and \\
Schrank, & Center Wiesbaden, & interpretation of clinical data \\
MD & Wiesbaden, Germany & $\begin{array}{l}\text { and drafted the manuscript } \\
\text { for intellectual content. }\end{array}$
\end{tabular}

\begin{tabular}{lll}
\hline Heidi & Ruhr-University Bochum, \\
Zhuge, BSc & Bochum, Germany & $\begin{array}{l}\text { Interpretation of data and } \\
\text { revised the manuscript for } \\
\text { intellectual content. }\end{array}$ \\
\hline
\end{tabular}

\begin{tabular}{|c|c|c|}
\hline $\begin{array}{l}\text { Zacharias } \\
\text { Orfanos, } \\
\text { PhD }\end{array}$ & $\begin{array}{l}\text { University of Bonn, Bonn, } \\
\text { Germany }\end{array}$ & $\begin{array}{l}\text { Acquisition and } \\
\text { interpretation of data. }\end{array}$ \\
\hline $\begin{array}{l}\text { Julius } \\
\text { Kostan, } \\
\text { PhD }\end{array}$ & $\begin{array}{l}\text { University of Vienna, } \\
\text { Vienna, Austria }\end{array}$ & $\begin{array}{l}\text { Acquisition and } \\
\text { interpretation of data. }\end{array}$ \\
\hline $\begin{array}{l}\text { Adekunle } \\
\text { Onipe, PhD }\end{array}$ & $\begin{array}{l}\text { University of Vienna, } \\
\text { Vienna, Austria }\end{array}$ & $\begin{array}{l}\text { Acquisition and } \\
\text { interpretation of data. }\end{array}$ \\
\hline $\begin{array}{l}\text { Dominik } \\
\text { Sellung, } \\
\text { MD }\end{array}$ & $\begin{array}{l}\text { Ruhr-University Bochum, } \\
\text { Bochum, Germany }\end{array}$ & $\begin{array}{l}\text { Interpretation of data and } \\
\text { revised the manuscript for } \\
\text { intellectual content. }\end{array}$ \\
\hline $\begin{array}{l}\text { Anne } \\
\text { Katrin } \\
\text { Güttsches, } \\
\text { MD }\end{array}$ & $\begin{array}{l}\text { Ruhr-University Bochum, } \\
\text { Bochum, Germany }\end{array}$ & $\begin{array}{l}\text { Interpretation of data and } \\
\text { revised the manuscript for } \\
\text { intellectual content. }\end{array}$ \\
\hline $\begin{array}{l}\text { Britta } \\
\text { Eggers, } \\
\text { PhD }\end{array}$ & $\begin{array}{l}\text { Ruhr-University Bochum, } \\
\text { Bochum, Germany }\end{array}$ & $\begin{array}{l}\text { Interpretation of proteomic } \\
\text { data. }\end{array}$ \\
\hline $\begin{array}{l}\text { Frank } \\
\text { Jacobsen, } \\
\text { PhD }\end{array}$ & $\begin{array}{l}\text { Ruhr-University Bochum, } \\
\text { Bochum, Germany }\end{array}$ & $\begin{array}{l}\text { Interpretation of data and } \\
\text { revised the manuscript for } \\
\text { intellectual content. }\end{array}$ \\
\hline
\end{tabular}

Wolfram University of Würzburg, Interpretation of data and

Kress, PhD Würzburg, Germany revised the manuscript for intellectual content.

\begin{tabular}{lll}
\hline $\begin{array}{l}\text { Katrin } \\
\text { Marcus, } \\
\text { PhD }\end{array}$ & $\begin{array}{l}\text { Ruhr-University Bochum, } \\
\text { Bochum, Germany }\end{array}$ & $\begin{array}{l}\text { Interpretation of proteomic } \\
\text { data. }\end{array}$ \\
\hline $\begin{array}{l}\text { Kristina } \\
\text { Djinovic- } \\
\text { Carugo, } \\
\text { PhD }\end{array}$ & $\begin{array}{l}\text { University of Vienna, } \\
\text { Vienna, Austria and } \\
\text { University of Ljubljana, }\end{array}$ & $\begin{array}{l}\text { Acquisition and } \\
\text { interpretation of data and } \\
\text { revised the manuscript for } \\
\text { intellectual content. }\end{array}$ \\
\hline $\begin{array}{l}\text { Peter F.M. } \\
\text { van der } \\
\text { Ven, PhD }\end{array}$ & $\begin{array}{l}\text { University of Bonn, Bonn, } \\
\text { Germany }\end{array}$ & $\begin{array}{l}\text { Acquisition and } \\
\text { interpretation of data and } \\
\text { revised the manuscript for } \\
\text { intellectual content. }\end{array}$ \\
\hline $\begin{array}{l}\text { Dieter O. } \\
\text { Fürst, PhD }\end{array}$ & $\begin{array}{l}\text { University of Bonn, Bonn, } \\
\text { Germany }\end{array}$ & $\begin{array}{l}\text { Acquisition and } \\
\text { interpretation of data and } \\
\text { drafted the manuscript for } \\
\text { intellectual content. }\end{array}$ \\
\hline $\begin{array}{l}\text { Matthias } \\
\text { Morgerd, }\end{array}$ & $\begin{array}{l}\text { Ruhr-University Bochum, } \\
\text { Bochum, Germany }\end{array}$ & $\begin{array}{l}\text { Major role in the acquisition } \\
\text { and analysis of data and } \\
\text { drafted the manuscript for } \\
\text { intellectual content. }\end{array}$ \\
\hline
\end{tabular}




\section{References}

1. Kley RA, Olivé M, Schröder R. New aspects of myofibrillar myopathies. Curr Opin Neurol 2016;29:628-634.

2. Schröder R, Schoser B. Myofibrillar myopathies: a clinical and myopathological guide. Brain Pathol 2009; 19:483-492.

3. Selcen D, Engel AG. Myofibrillar myopathies. Handb Clin Neurol 2011;101:143-154.

4. Vorgerd M, van der Ven PFM, Bruchertseifer V, et al. A mutation in the dimerization domain of filamin c causes a novel type of autosomal dominant myofibrillar myopathy. Am J Hum Genet 2005; 77:297-304.

5. Kley RA, Hellenbroich Y, van der Ven PFM, et al. Clinical and morphological phenotype of the filamin myopathy: a study of 31 German patients. Brain 2007;130:3250-3264.

6. Kley RA, van der Ven PFM, Olivé M, et al. Impairment of protein degradation in myofibrillar myopathy caused by FLNC/filamin C mutations. Autophagy 2013;9:422-423.

7. Verdonschot JAJ, Vanhoutte EK, Claes GRF, et al. A mutation update for the FLNC gene in myopathies and cardiomyopathies. Hum Mutat 2020;41:1091-1111.

8. Shatunov A, Olivé $\mathrm{M}$, Odgerel $\mathrm{Z}$, et al. In-frame deletion in the seventh immunoglobulin-like repeat of filamin $\mathrm{C}$ in a family with myofibrillar myopathy. Eur J Hum Genet 2009; 17:656-663.

9. Lee $\mathrm{HH}$, Wong $\mathrm{S}$, Sheng B, et al. Clinical and pathological characterization of FLNCrelated myofibrillar myopathy caused by founder variant c.8129G $>$ A in Hong Kong Chinese. Clin Genet 2020;97:747-757.

10. Fischer D, Kley RA, Strach K, et al. Distinct muscle imaging patterns in myofibrillar myopathies. Neurology 2008;71:758-765.

11. Fürst DO, Goldfarb LG, Kley RA, Vorgerd M, Olivé M, van der Ven PFM. Filamin C-related myopathies: pathology and mechanisms. Acta Neuropathol 2013;125:33-46.

12. Wattjes MP, Kley RA, Fischer D. Neuromuscular imaging in inherited muscle diseases. Eur Radiol 2010;20:2447-2460.

13. Duff RM, Tay V, Hackman P, et al. Mutations in the N-terminal actin-binding domain of filamin C cause a distal myopathy. Am J Hum Genet 2011;88:729-740.

14. Guergueltcheva V, Peeters K, Baets J, et al. Distal myopathy with upper limb predominance caused by filamin C haploinsufficiency. Neurology 2011;77:2105-2114.

15. Maerkens A, Kley RA, Olivé M, et al. Differential proteomic analysis of abnormal intramyoplasmic aggregates in desminopathy. J Proteomics 2013;90:14-27.

16. Himmel M, van der Ven PFM, Stocklein W, Fürst DO. The limits of promiscuity: isoform-specific dimerization of filamins. Biochemistry 2003;42:430-439.

17. Pudas R, Kiema TR, Butler PJ, Stewart M, Ylanne J. Structural basis for vertebrate filamin dimerization. Structure 2005;13:111-119.

18. Linnemann A, van der Ven PFM, Vakeel P, et al. The sarcomeric Z-disc component myopodin is a multiadapter protein that interacts with filamin and alpha-actinin. Eur J Cell Biol 2010;89:681-692.

19. Faulkner G, Pallavicini A, Comelli A, et al. FATZ, a filamin-, actinin-, and telethonin-binding protein of the Z-disc of skeletal muscle. J Biol Chem 2000;275: 41234-41242.

20. Frey N, Olson EN. Calsarcin-3, a novel skeletal muscle-specific member of the calsarcin family, interacts with multiple Z-disc proteins. J Biol Chem 2002;277:13998-14004.

21. Takada F, Vander Woude DL, Tong HQ et al. Myozenin: an alpha-actinin- and gamma-filamin-binding protein of skeletal muscle Z lines. Proc Natl Acad Sci U S A 2001;98:1595-1600.
22. Molt S, Bührdel JB, Yakovlev S, et al. Aciculin interacts with filamin C and Xin and is essential for myofibril assembly, remodeling and maintenance. J Cell Sci 2014;127:3578-3592.

23. Gontier Y, Taivainen A, Fontao L, et al. The Z-disc proteins myotilin and FATZ-1 interact with each other and are connected to the sarcolemma via muscle-specific filamins. J Cell Sci 2005;118:3739-3749.

24. van der Ven PFM, Wiesner S, Salmikangas P, et al. Indications for a novel muscular dystrophy pathway. gamma-filamin, the muscle-specific filamin isoform, interacts with myotilin. J Cell Biol 2000;151:235-248.

25. Thompson TG, Chan YM, Hack AA, et al. Filamin 2 (FLN2): a muscle-specific sarcoglycan interacting protein. J Cell Biol 2000;148:115-126.

26. Odgerel Z, van der Ven PFM, Fürst DO, Goldfarb LG. DNA sequencing errors in molecular diagnostics of filamin myopathy. Clin Chem Lab Med 2010;48:1409-1414.

27. Kley RA, Maerkens A, Leber Y, et al. A combined laser microdissection and mass spectrometry approach reveals new disease relevant proteins accumulating in aggregates of filaminopathy patients. Mol Cell Proteomics 2013;12:215-227.

28. Maerkens A, Olivé M, Schreiner A, et al. New insights into the protein aggregation pathology in myotilinopathy by combined proteomic and immunolocalization analyses. Acta Neuropathol Commun 2016;4:8.

29. Kley RA, Serdaroglu-Oflazer P, Leber Y, et al. Pathophysiology of protein aggregation and extended phenotyping in filaminopathy. Brain 2012;135:2642-2660.

30. van den Bogaart FJ, Claeys KG, Kley RA, et al. Widening the spectrum of filamin-C myopathy: predominantly proximal myopathy due to the p.A193T mutation in the actin-binding domain of FLNC. Neuromuscul Disord 2017;27:73-77.

31. Walter MC, Reilich P, Huebner A, et al. Scapuloperoneal syndrome type Kaeser and a wide phenotypic spectrum of adult-onset, dominant myopathies are associated with the desmin mutation R350P. Brain 2007;130:1485-1496.

32. Ulbricht A, Eppler FJ, Tapia VE, et al. Cellular mechanotransduction relies on tensioninduced and chaperone-assisted autophagy. Curr Biol 2013;23:430-435.

33. Juo LY, Liao WC, Shih YL, Yang BY, Liu AB, Yan YT. HSPB7 interacts with dimerized FLNC and its absence results in progressive myopathy in skeletal muscles. J Cell Sci 2016;129:1661-1670.

34. Greenberg SA, Salajegheh M, Judge DP, et al. Etiology of limb girdle muscular dystrophy $1 \mathrm{D} / 1 \mathrm{E}$ determined by laser capture microdissection proteomics. Ann Neurol 2012;71:141-145.

35. Schessl J, Zou Y, McGrath MJ, et al. Proteomic identification of FHL1 as the protein mutated in human reducing body myopathy. J Clin Invest 2008;118:904-912.

36. Stenson PD, Mort M, Ball EV, et al. The Human Gene Mutation Database: towards a comprehensive repository of inherited mutation data for medical research, genetic diagnosis and next-generation sequencing studies. Hum Genet 2017;136:665-677.

37. Ball EV, Stenson PD, Abeysinghe SS, Krawczak M, Cooper DN, Chuzhanova NA. Microdeletions and microinsertions causing human genetic disease: common mechanisms of mutagenesis and the role of local DNA sequence complexity. Hum Mutat 2005;26:205-213.

38. Chevessier F, Schuld J, Orfanos Z, et al. Myofibrillar instability exacerbated by acute exercise in filaminopathy. Hum Mol Genet 2015;24:7207-7220.

39. Löwe T, Kley RA, van der Ven PFM, et al. The pathomechanism of filaminopathy: altered biochemical properties explain the cellular phenotype of a protein aggregation myopathy. Hum Mol Genet 2007;16:1351-1358. 


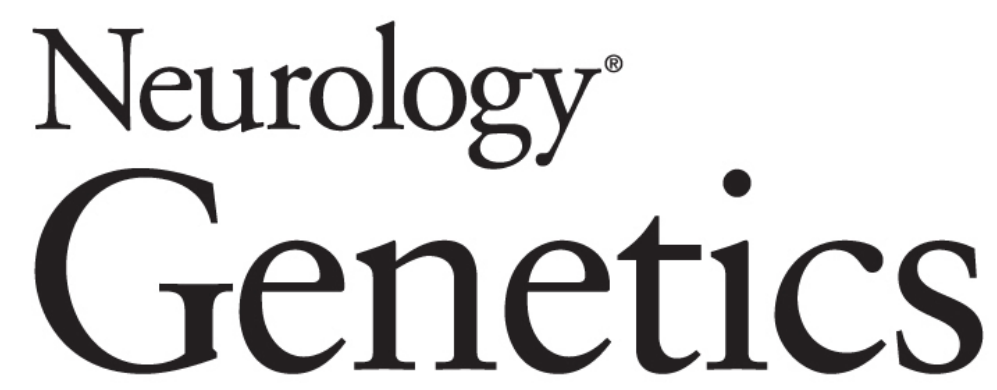

FLNC-Associated Myofibrillar Myopathy: New Clinical, Functional, and Proteomic Data

Rudolf Andre Kley, Yvonne Leber, Bertold Schrank, et al. Neurol Genet 2021;7;

DOI 10.1212/NXG.0000000000000590

This information is current as of June 1, 2021

Neurol Genet is an official journal of the American Academy of Neurology. Published since April 2015, it is an open-access, online-only, continuous publication journal. Copyright Copyright ( 2021 The Author(s). Published by Wolters Kluwer Health, Inc. on behalf of the American Academy of Neurology.. All rights reserved. Online ISSN: 2376-7839.

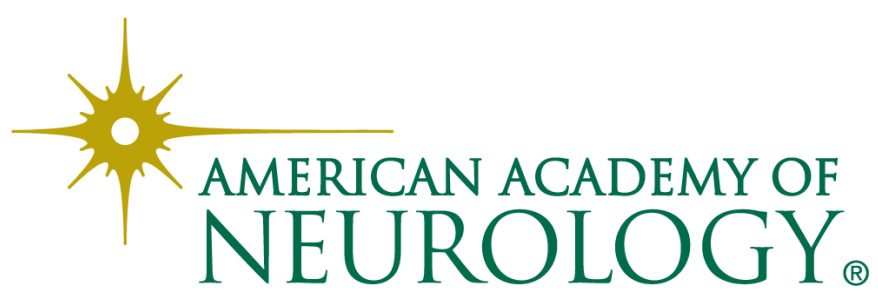




\section{Updated Information \& Services}

References

Citations

Subspecialty Collections

Permissions \& Licensing

Reprints including high resolution figures, can be found at: http://ng.neurology.org/content/7/3/e590.full.html

This article cites 38 articles, 9 of which you can access for free at: http://ng.neurology.org/content/7/3/e590.full.html\#\#ref-list-1

This article has been cited by 1 HighWire-hosted articles: http://ng.neurology.org/content/7/3/e590.full.html\#\#otherarticles

This article, along with others on similar topics, appears in the following collection(s):

\section{All Genetics}

http://ng.neurology.org//cgi/collection/all_genetics

Clinical neurology examination

http://ng.neurology.org//cgi/collection/clinical_neurology_examination

\section{EMG}

http://ng.neurology.org//cgi/collection/emg

MRI

http://ng.neurology.org//cgi/collection/mri

Muscle disease

http://ng.neurology.org//cgi/collection/muscle_disease

Information about reproducing this article in parts (figures,tables) or in its entirety can be found online at:

http://ng.neurology.org/misc/about.xhtml\#permissions

Information about ordering reprints can be found online: http://ng.neurology.org/misc/addir.xhtml\#reprintsus

Neurol Genet is an official journal of the American Academy of Neurology. Published since April 2015, it is an open-access, online-only, continuous publication journal. Copyright Copyright $\odot 2021$ The Author(s). Published by Wolters Kluwer Health, Inc. on behalf of the American Academy of Neurology.. All rights reserved. Online ISSN: 2376-7839.

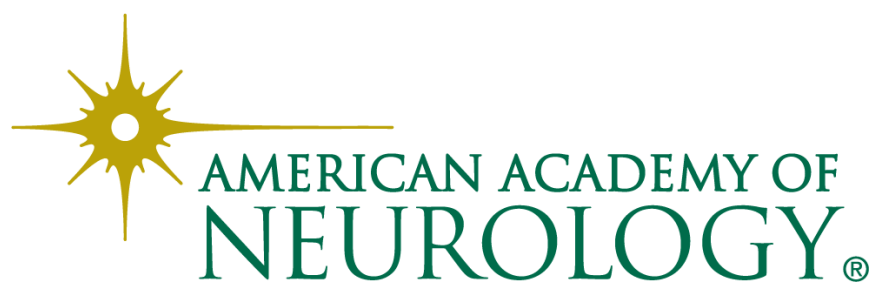

